\title{
Numerical Investigation of Seismic Response of Hybrid Buckling Restrained Braced Frames
}

\author{
Nader Hoveidae ${ }^{1 *}$ \\ ${ }^{1}$ Department of civil Engineering. Faculty of Engineering, \\ Azarbaijan Shahid Madani University, \\ Tabriz, Iran \\ *Corresponding author, e-mail: hoveidaei@azaruniv.ac.ir
}

Received: 04 February 2018, Accepted: 18 November 2018, Published online: 06 December 2018

\begin{abstract}
The Conventional buckling restrained braces used in concentrically braced frames are expected to yield in both tension and compression without major degradation of capacity under severe seismic ground motions. One of the weakness points of a standard buckling restrained braced frame is the low post-yield stiffness and thus large residual deformation under moderate to severe ground motions. This phenomenon can be related to the low post-yield stiffness of the core segment in comparison to its elastic stiffness. This paper investigates the application of stainless steel as the core material in a hybrid buckling restrained brace. The "hybrid" term arises from the use of more than one core component with different steel materials, including high strength high-performance steel and stainless steel (304L) with high strain hardening in the core of buckling restrained brace. Nonlinear dynamic time history analyses were conducted on a variety of diagonally braced frames with different heights, in order to compare the seismic performance of standard (non-hybrid) and hybrid buckling restrained braced frames. The results showed that the proposed hybrid buckling restrained braces reduce the inter-story and specially the residual drift demands in buckling restrained braced frames.
\end{abstract}

Keywords

buckling restrained brace, hybrid core, nonlinear dynamic time history analysis, story drift, residual story drift

\section{Introduction}

Buckling Restrained Braced Frames (BRBFs) for seismic load carrying, have been broadly used in recent years. The behaviour of a Buckling Restrained Brace (BRB) varies from a conventional brace element because it yields in both tension and compression without significant degradation of compressive capacity.

A conventional buckling restrained brace member is typically comprised of a steel core and a buckling restraining component such as a mortar filled steel tube. The restrainer inhibits the brace overall buckling and minimizes its local buckling. Therefore, the core can yield in compression as well as tension. Several findings exist on BRBs' seismic performance in the literature. Black et al. [1] performed component testing of BRBs and modeled a hysteretic curve to compare the test results and found that the hysteretic curve of a BRB is stable, symmetrical, and ample. Inoue et al. [2] introduced buckling restrained braces as hysteretic dampers to increase the ductility of building structures. Xie [3] examined the use of BRBs for practical applications for buildings in Asia. Clark et al. [4] proposed a design method for buildings including BRBs. Sabelli et al. [5] investigated seismic demands on BRBs through nonlinear time history analysis of BRB frames.

Hoveidae et al. [6] investigated the global buckling behaviour of all-steel BRBs through extensive finite element analysis method. Guo et al. [7] proposed a new type of BRBs namely Core-Separated Buckling-Restrained Brace (CSBRB), and hypothetically and experimentally investigated the behaviour of the brace. The results showed that the material utilization efficiency of the CSBRB is significantly improved compared with common BRB, since its cross-section spreads outwards by spacing two cores, thus improving the flexural rigidity of the restraining system.

The significant shortcoming of an ordinary buckling restrained braced frame is the low post-yield stiffness and consequently large residual deformation under moderate to severe ground motions. Current studies have revealed 
that residual drifts after tremors that are greater than $0.5 \%$ in structures may characterize a complete loss of the structure from an economic view.

Recent studies $[8,9,10]$ have shown that it is necessary to consider these residual drifts to fully characterize the performance of a structural system after a seismic excitation and the prospective destruction that the system has suffered.

McCormick et al. [11] conducted a study of one occupied building at Kyoto University in Japan and conducted a review of previous research in Japan, including consideration of both physiological and psychological effects of residual drifts on inhabitants. They concluded that residual drifts of $0.5 \%$ are generally perceivable by occupants, and occupants of a building experience dizziness and nausea as residual drifts approach $1.0 \%$. More decisively, they concluded that in Japan it was generally less costly to rebuild a structure than to repair it when an earthquake resulted in residual drifts greater than $0.5 \%$. The quantification of residual deformations of BRBFs and Special Moment-Resisting Frames (SMRFs) has been formerly investigated by Sabelli et al. [5], who numerically examined the response of 3 and 6-story buckling restrained braced frames subjected to a set of Design Based Earthquake (DBE) ground motions and computed average of maximum residual story drifts of 0.5 and $0.7 \%$, respectively. Under a set of Maximum Considered Earthquake (MCE) ground motions, the mean residual drift value amplified to $2.2 \%$.

Pettinga et al. [12] performed nonlinear analyses of 4-story BRBFs and found the average maximum residual story drifts between 0.85 and $0.89 \%$ when subjected to New Zealand design-level earthquakes. Fahnestock et al. [13] performed nonlinear analyses on a 4-story BRB frame and determined that the mean maximum residual story drifts were 0.5 and $1.2 \%$ under DBE and MCE ground motion ensembles, respectively. In hybrid testing of the same scaled-down frame, the observed experimental maximum residual story drifts were determined to be $0.2,1.3$, and $2.7 \%$ under individual ground motions representing the Frequently Occurring Earthquake (FOE, probability of occurrence of $50 \%$ in 50 years), DBE, and MCE levels, respectively [14]. Similarly, nonlinear analyses directed by Tremblay et al. [15] predicted median residual drifts varying between 0.84 and $1.38 \%$ under DBE ground motions for 2 to 16 -story BRB frames.

Hoveidae et al. [16] proposed a new type of buckling restrained brace, called short-core all-steel buckling restrained brace, in which a shorter core component was serially connected to a semi rigid non-yielding member. The results of extensive nonlinear time history analyses showed that the short-core BRBs (SCBRB) can considerably reduce the residual drifts of BRBFs. Chou et al. [17] experimentally and theoretically investigated the seismic response of dual-core self-centering sandwiched BRBs. The results indicated that the proposed BRBs provide stable hysteretic response and high energy dissipation capacity before low cycle fatigue fracture. Moreover, Teran et al. [18] studied the seismic response of dual buckling restrained braced frames. They determined that if the flexible moment resisting frames provide at least one-sixth of the lateral stiffness of the dual structural system while remaining practically undamaged after the ground motion, the system will show adequate self-centering behaviour in spite of the fact that the bracing system may develop significant plastic behaviour. Dong et al. [19] proposed an innovative self-centering buckling restrained bracing system for mitigating seismic response of bridge structures with double column piers. The research results indicated that the proposed system can reduce residual drifts and exhibited moderate energy dissipation capacity.

Recently, Atlayan and Charney [20] studied the behaviour of hybrid BRBFs in which a multi-material core component including Low-Yield-Point steel (LYP), HighPerformance Steel (HPS)-70W, and A36 steel was implemented. The results showed that the hybrid BRBF experiences significantly smaller residual drifts in comparison to non-hybrid BRBFs.

The main objective of this paper is to introduce a different type of hybrid buckling restrained brace in order to have a better control on inter-story and especially residual drift demands. LYP grade steel is available in plates in Japan market, but currently not available in other markets such as Iran. Due to the low yield point and high ductility, the LYP grades have been specifically developed and studied extensively for the development of the axial-yield type hysteretic dampers [20]. Another alternative for highly ductile, low strength steel, is stainless steel (SS). The substantially greater isotropic cyclic strain hardening behaviour (dilation of the yield surface) of stainless steel is well known. Both LYP and stainless steel materials possess high strain hardening characteristics. However, stainless steel is more durable, and has excellent corrosion resistance. Furthermore, unlike LYP steel, stainless steel is available in a wide variety of sizes and sections. Nevertheless, LYP steels are more ductile and have lower yielding strengths, in comparison to stainless steels. 
Table 1 Steel material properties used in standard and hybrid BRBs

\begin{tabular}{lccc}
\hline & A572-G50 & HPS-70W & SS(304L) \\
\hline $\mathrm{F}_{\mathrm{y}}(\mathrm{Mpa})$ & 353 & 503 & 252 \\
$\mathrm{E}(\mathrm{GPa})$ & 186.2 & 201.3 & 194.5 \\
\hline
\end{tabular}

Table 2 Material combination in standard and hybrid BRBs

\begin{tabular}{lccc}
\hline & Material & Standard RB & Hybrid BRB \\
\hline Area ratio & A572-G50 & 1.00 & - \\
& HPS-70W & - & 0.46 \\
& SS (304L) & - & 0.48 \\
Stiffness $(\mathrm{kN} / \mathrm{cm})$ & - & $18620 \mathrm{~A} / \mathrm{L}$ & \\
Strength $(\mathrm{kN})$ & - & $35.3 \mathrm{~A}$ & $35.3 . \mathrm{A}$ \\
\hline
\end{tabular}

This paper aims to investigate the possibility of using stainless steel together with a high performance steel as BRB core materials. In this type of hybrid BRB, the stainless steel component of the BRB core yields earlier than the carbon steel and the energy dissipation due to early yielding helps the hybrid BRBF to minimize the response under low to mid-level tremors. The main purposes are to acquire better performance, to minimize the residual displacements at design basis and maximum considered earthquake (DBE and MCE) levels, and to increase the reliability of the existing systems. Hybrid BRBs can be developed in different detailing. The core components may be encased by a concrete filled steel tube. An all-steel encasing system can also be implemented in a hybrid BRB which benefits the fabrication facilities.

\section{Hybrid BRB material combinations}

Hybrid BRBs proposed in this paper are developed by combining two steel materials with different yield strengths in a single hybrid brace. It is supposed that different steel cores are connected in parallel; The paper aims to compare the seismic performance of hybrid and non-hybrid (i.e. standard) BRBFs. The total brace stiffness and strength in a hybrid BRB are kept.

the same as the standard BRB during the brace design process. The stiffness is not changed in order to make a distinct and real comparison between standard and hybrid BRBFs. In this case, the standard and hybrid BRBs will absorb the same level of seismic force. Also, since the beam and column design in BRBFs depends on the adjusted brace strengths, the total strength of the brace was kept unchanged so that the same beam and column sections could be used in standard and hybrid BRBFs. Tables 1 and 2 provide material properties and combinations of steel material used in the core of standard and hybrid BRBs.
In Table 2, the core area ratios, total stiffness, and total strength values for standard and hybrid BRBs are shown, in which the core area (A) and length (L) are in terms of $\mathrm{cm} 2$ and $\mathrm{cm}$, respectively. The steel core areas in BRBFs are specified in a way that total stiffness and strength of standard and hybrid BRBs will be the same. In the standard BRBF, only structural steel A572-G50 with yielding strength of $353 \mathrm{MPa}$ was implemented. However, in hybrid BRBs, stainless steel 304L type, and high performance steel HPS-70W were used as core materials. Since, the core of a BRB is a small part in comparison to other structural elements, the application of stainless as a part of brace core does not significantly affect the total cost of construction [20]. A possible cross section of a hybrid BRB is illustrated in Fig. 1.

\section{Material calibration}

In order to accurately capture the response of structural models during nonlinear dynamic time history analysis, material calibration is conducted for cyclic response of steel materials used in BRB core. For this purpose, cyclic test results conducted by Dusicka et al. [21] were used to calibrate the cyclic properties of HPS-70W and A572-G50 steels. In addition, the test results by Beaumont and Annan [22] were used for calibration of cyclic response of stainless steel. The calibration of material was made in OpenSees [23]. For this purpose, the Giuffre-MenegottoPinto (Steel02) material model was implemented to simulate HPS-70W and A572-G50 steels. Furthermore, a Ramberg-Osgood model was adopted to the cyclic response of stainless steel material [22]. Fig. 2 represents the calibrated cyclic response of different steel materials. The cyclic calibrated material data was applied in nonlinear time history analysis.

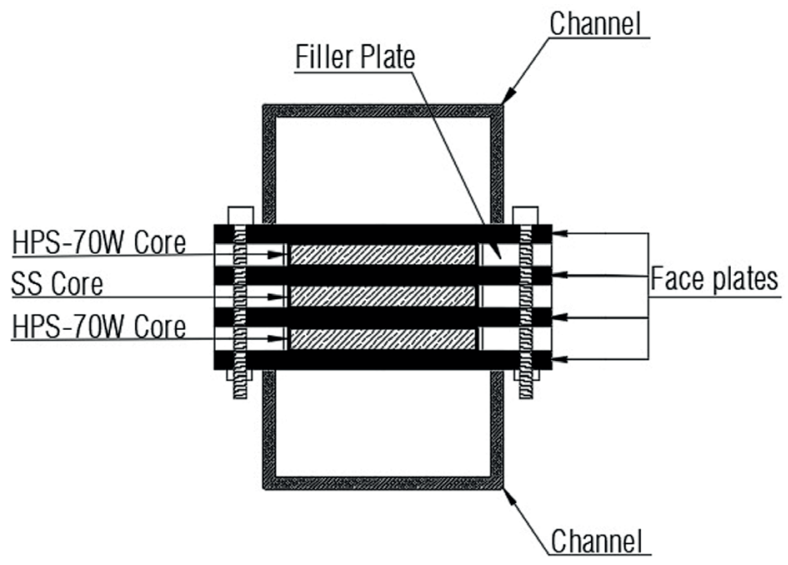

Fig. 1 Cross section of proposed hybrid BRB 

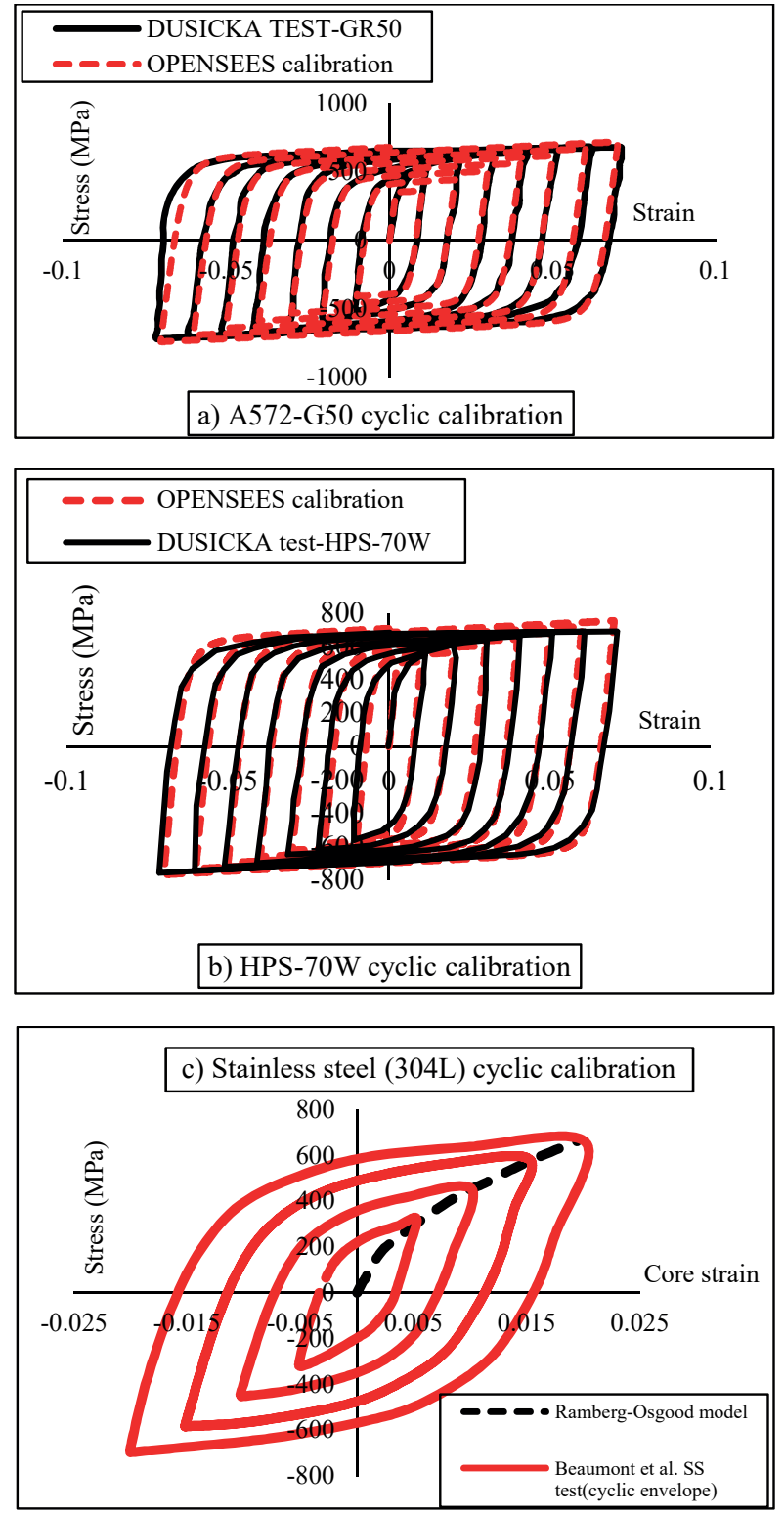

Fig. 2 a) to c) Calibration of cyclic response of different materials

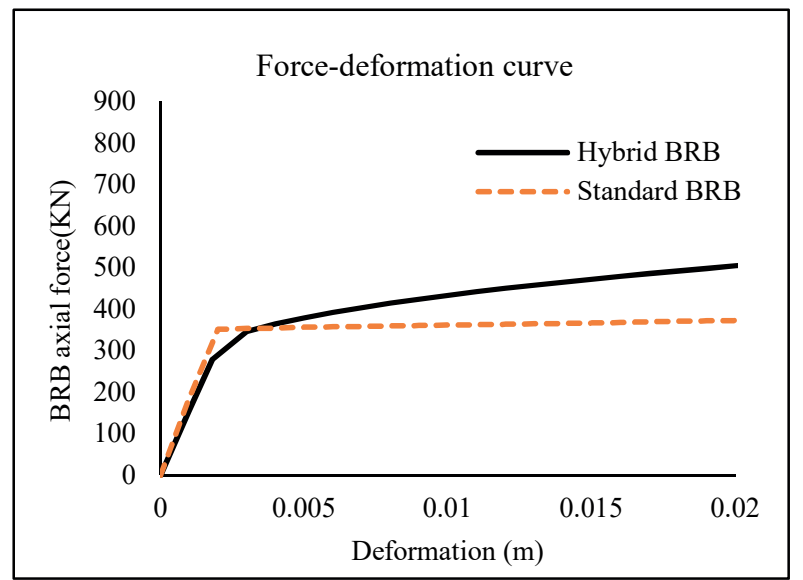

Fig. 3 Comparison of force-deformation relation in standard and hybrid BRBs

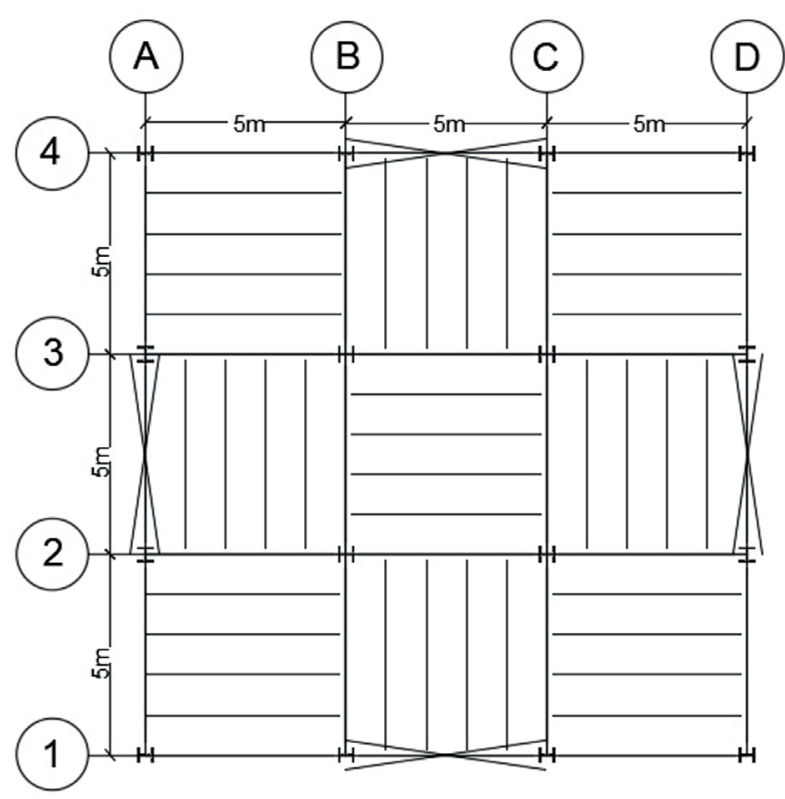

Fig. 4 Plan view of archetype buildings

For a better understanding of the response of standard and hybrid BRBs, first, single BRB models were created in Opensees, and the force-deformation response of standard and hybrid BRBs were captured up to the core strain of $2 \%$. As illustrated in Fig.3, the force-deformation relation of the standard BRB is bi-linear. However, the hybrid BRB exhibits a different response. The force-deformation of hybrid BRB is tri-linear. This is due to two-phase yielding process of the core in hybrid BRB. The stainless steel core yields prior to the G70 core. After that, the G70 core yields and at this point, the entire hybrid brace possesses a yielding force equal to that in the standard BRB, as expected from the preliminary design. In these verification models, the core area and length in standard BRB were set to unity for simplicity, and the area ratios represented in table 2, were considered for hybrid BRB cores.

A steel02 material was adopted for G70 and grade 50 steel materials. Furthermore, a Romberg-Osgood model [22] was specified for the stainless steel material. A truss element was used to model the BRBs. The comparison of cyclic responses of standard (G50) and hybrid BRBs including $\mathrm{G} 70$ and stainless steels as core materials are provided in Fig. 3. As illustrated in Fig. 3, the hybrid BRB possess higher strain hardening properties compared to standard BRB with the same axial yielding strength and elastic stiffness.

\section{Design of Building Models}

With the aim of comparing the seismic behaviour of standard and hybrid BRBFs, nonlinear dynamic time history analyses on low to mid-rise archetypes including 4-story, 
10 -story, and 14-story diagonally braced frames were conducted. In the Iranian building documents, the structure height for bracing the singular lateral resisting system is limited to 50 meters. This allows having buildings with the selected story ranges and at most, 14 stories. The story height is set to $3.2 \mathrm{~m}$ which is a typical value in building construction. The braced frames are selected from

code-based designed buildings. For this purpose, the archetype buildings are designed according to Iranian Earthquake code [24] using ETABS software. Table 3 summarizes the seismic data for building models used for design purpose. Dead loads of 5.2 and $5.6 \mathrm{kN} / \mathrm{m}^{2}$ were assigned for stories and roof, respectively. In addition, the live loads assigned to the stories and roof were 2.0 and $1.5 \mathrm{kN} / \mathrm{m} 2$, respectively. The design procedure included the p-delta effects as well. The Young modulus, yielding stress, and Poisson ratio of A572 (G50) steel material were set to $186.2 \mathrm{GPa}, 353 \mathrm{MPa}$, and 0.3 , respectively. AISC regulations were used for design of steel frames [25]. Fig. 4 illustrates the plan view of archetype models. W14 $\times 22$ was assigned for all beam elements in archetype models. Tables 4 and 5 summarize the designed section of columns and BRB core areas, respectively.

As illustrated in Fig. 4, frame-1 is considered for conducting two dimensional dynamic time history analysis in OpenSees software.

\section{Description of 2D models in OpenSees}

Two dimensional nonlinear dynamic time history analyses were conducted in OpenSees to evaluate the seismic response of diagonally braced standard and hybrid BRBFs. As discussed former, in order to compare the seismic response of standard and hybrid BRBFs, the lateral stiffness of standard and hybrid BRBFs are kept constant. The capability of hybrid BRBs to reduce lateral inter-story and residual drifts was evaluated through nonlinear dynamic time history analysis, and totally 264 analyses were conducted in OpenSees. The two dimensional braced frames were assumed to have pinned connection at beam ends and also at the bases. Columns in the braced spans were oriented to resist lateral forces through strong-axis bending. Force- beam- column elements with fiber section were used to model beams and columns. The BRB elements included two parts serially connected together, one part which represents the yielding portion of the brace core was modeled by a nonlinear force-beam-column element. The latter part of BRB was modeled using elastic-beam-column element which represents the brace end-connection part and also
Table 3 Seismic data for archetype building models

\begin{tabular}{lc}
\hline Site Class & $\mathrm{D}$ \\
\hline PGA & $0.35 \mathrm{~g}$ \\
Importance factor & 1 \\
Response modification factor & 7 \\
Base shear ratio, 4-story & 0.1375 \\
Base shear ratio, 10-story & 0.117 \\
Base shear ratio, 14-story & 0.0925 \\
\hline
\end{tabular}

Table 4 BRB core areas $\left(\mathrm{cm}^{2}\right)$

\begin{tabular}{ccc}
\hline $4-$ Story & 10 -Story & $14-$ Story \\
\hline 39 & 90 & 87.5 \\
37.5 & 90 & 75 \\
26 & 75 & 75 \\
16 & 75 & 72.5 \\
- & 70 & 72.5 \\
- & 70 & 66 \\
- & 52 & 66 \\
- & 45 & 54 \\
- & 42 & 54 \\
- & 28 & 54 \\
- & - & 54 \\
- & - & 52 \\
- & - & 52 \\
- & - & 36 \\
\hline
\end{tabular}

Table 5 Specification of columns in archetype models

\begin{tabular}{lccc}
\hline Story & Column sections & & \\
\hline & 4 -Story & 10 -Story & 14 -Story \\
1 & $\mathrm{w} 14 \times 109$ & $\mathrm{w} 14 \times 500$ & $\mathrm{w} 14 \times 730$ \\
2 & $\mathrm{w} 14 \times 109$ & $\mathrm{w} 14 \times 500$ & $\mathrm{w} 14 \times 730$ \\
3 & $\mathrm{w} 14 \times 48$ & $\mathrm{w} 14 \times 342$ & $\mathrm{w} 14 \times 550$ \\
4 & $\mathrm{w} 14 \times 48$ & $\mathrm{w} 14 \times 342$ & $\mathrm{w} 14 \times 550$ \\
5 & - & $\mathrm{w} 14 \times 233$ & $\mathrm{w} 14 \times 398$ \\
6 & - & $\mathrm{w} 14 \times 233$ & $\mathrm{w} 14 \times 398$ \\
7 & - & $\mathrm{w} 14 \times 120$ & $\mathrm{w} 14 \times 342$ \\
8 & - & $\mathrm{w} 14 \times 120$ & $\mathrm{w} 14 \times 342$ \\
9 & - & $\mathrm{w} 14 \times 53$ & $\mathrm{w} 14 \times 233$ \\
10 & - & $\mathrm{w} 14 \times 53$ & $\mathrm{w} 14 \times 233$ \\
11 & - & - & $\mathrm{w} 14 \times 120$ \\
12 & - & - & $\mathrm{w} 14 \times 120$ \\
13 & - & - & $\mathrm{w} 14 \times 61$ \\
14 & - & & $\mathrm{w} 14 \times 61$ \\
\hline
\end{tabular}

non-yielding portion of the core plates. Based on the previous studies, in a common $\mathrm{BRB}$, the length of yielding part of the core segment is approximately equal to $50 \%$ of work- point to work-point length of the brace [16]. The zero-length elements were used to model pinned 
connection of beam and brace ends. To consider P-delta effects, a leaning column was used in the model. Leaning columns were included to account for the additional stiffness required at each level in order to calibrate the model, which additional stiffness represents the combined stiffening effect of those elements of the building not explicitly included in the two dimensional model (e.g. non-structural components, partition walls, etc.). In order to adjust the stiffness of the leaning columns, the moment of inertia of the elements was simply increased or decreased as required. The leaning columns were tied to the gravity frame by means of rigid links with pinned ends at each level. Gravity loads were applied to the frame at each level based upon tributary area of the dead and live loads. A co-rotational geometric transformation was assigned to beam, columns, and brace elements. Inherent damping was considered as Rayleigh damping by setting the critical damping ratio to $2 \%$ at the fundamental and third modes of the structure. Steel02 material with isotropic hardening rule was assigned to all beams, columns, and BRBs. The hardening parameters of the steel were introduced to the model based on the calibration data represented in Fig. 2. Furthermore, an Opensees model of 4-story braced frame is depicted in Fig. 5.

In the hybrid BRBF system, it was assumed that different steel cores are connected in parallel, thus, in the numerical model, two brace elements were assigned on top of each other. The rigid diaphragms at the story levels were modeled using the constraint of equal degree of freedom of story nodes. A lumped mass system was considered in dynamic time history analysis.

\section{Nonlinear dynamic time history analysis 6.1 Selection of ground motion records}

Earthquake engineering practice is gradually using nonlinear response history analysis to investigate the performance of structures. This thorough technique of time his-

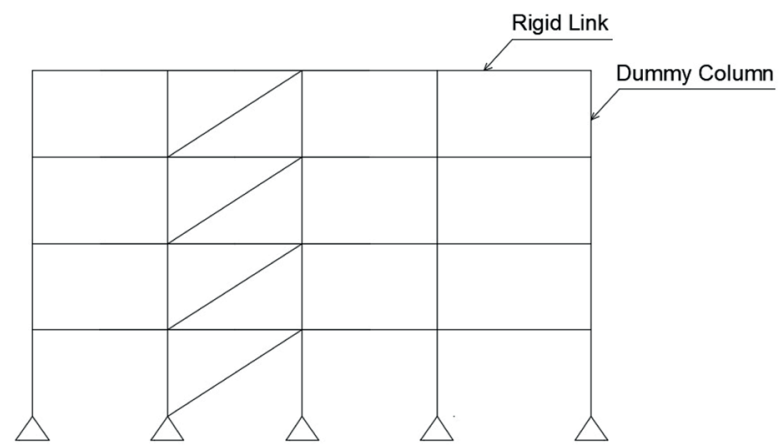

Fig. 5 The sketch of 4-story BRBF in OpenSees tory analysis requires selection and scaling of ground motion records appropriate to selected hazard levels. Thus, ground motions are scaled to characterize a range of earthquake intensities up to collapse level ground motions. In this paper, twenty-two far-field ground motion records suggested by ATC-63 [26] were selected to perform nonlinear time history analyses. Table 6 summarizes the selected records and their specifications. Two hazard levels were selected for the analysis, first the DBE level which corresponds to the design basis earthquake with an occurrence probability of $10 \%$ in 50 years, and the latter MCE level which corresponds to the maximum considerable earthquake with occurrence probability of $2 \%$ in 50 years.

SeismoMatch [27] software was used to closely scale and match the selected records to the DBE and MCE earthquakes for periods ranging from $0.2 \mathrm{~T}$ to $1.5 \mathrm{~T}$, where $\mathrm{T}$ is the natural period of the structure in the fundamental mode for the direction of response being analysed. The target DBE and MCE earthquakes were assumed as the design earthquake for soil type III, and 1.5 times the design earthquake, respectively, which can be found in the Iranian seismic code for buildings [24].

Table 6 Specifications of near-fault seismic records (ATC63)

\begin{tabular}{|c|c|c|c|c|}
\hline No. & Mag. & Year & Event & PGA $(g)$ \\
\hline 1 & 6.7 & 1994 & Northridge & 0.52 \\
\hline 2 & 6.7 & 1994 & Northridge & 0.48 \\
\hline 3 & 7.1 & 1999 & Duzce, Turkey & 0.82 \\
\hline 4 & 7.1 & 1999 & Hector Mine & 0.34 \\
\hline 5 & 6.5 & 1979 & Imperial Valley & 0.35 \\
\hline 6 & 6.5 & 1979 & Imperial Valley & 0.38 \\
\hline 7 & 6.9 & 1995 & Kobe, Japan & 0.51 \\
\hline 8 & 6.9 & 1995 & Kobe, Japan & 0.24 \\
\hline 9 & 7.5 & 1999 & Kocaeli, Turkey & 0.36 \\
\hline 10 & 7.5 & 1999 & Kocaeli, Turkey & 0.22 \\
\hline 11 & 7.3 & 1992 & Landers & 0.24 \\
\hline 12 & 7.3 & 1992 & Landers & 0.42 \\
\hline 13 & 6.9 & 1989 & Loma Prieta & 0.53 \\
\hline 14 & 6.9 & 1989 & Loma Prieta & 0.56 \\
\hline 15 & 7.4 & 1990 & Manjil, Iran & 0.51 \\
\hline 16 & 6.5 & 1987 & Superstition & 0.36 \\
\hline 17 & 6.5 & 1987 & Superstition & 0.45 \\
\hline 18 & 7 & 1992 & Cape & 0.55 \\
\hline 19 & 7.6 & 1999 & Chi-Chi, & 0.44 \\
\hline 20 & 7.6 & 1999 & Chi-Chi, & 0.51 \\
\hline 21 & 6.6 & 1971 & San Fernando & 0.21 \\
\hline 22 & 6.5 & 1976 & Friuli, Italy & 0.35 \\
\hline
\end{tabular}


Table 7 IDR and RDR demands in hybrid BRBFs (\%)

\begin{tabular}{lcccc}
\hline & \multicolumn{2}{c}{ MCE Hazard } & \multicolumn{2}{c}{ DBE Hazard } \\
Model & $\mathrm{RDR}_{\max }$ & $\mathrm{IDR}_{\max }$ & $\mathrm{RDR}_{\max }$ & $\mathrm{IDR}_{\max }$ \\
\hline 4story & 0.24 & 1.42 & 0.15 & 0.55 \\
10story & 0.32 & 1.85 & 0.25 & 1.52 \\
14story & 0.28 & 1.85 & 0.21 & 1.43 \\
\hline
\end{tabular}

Table 8 IDR and RDR demands in standard BRBFs (\%)

\begin{tabular}{lcccc}
\hline & \multicolumn{2}{c}{ MCE Hazard } & \multicolumn{2}{c}{ DBE Hazard } \\
Model & RDR $_{\max }$ & IDR $_{\max }$ & RDR $_{\max }$ & IDR $_{\max }$ \\
\hline 4story & 0.54 & 1.60 & 0.29 & 0.70 \\
10story & 0.70 & 2.17 & 0.50 & 1.77 \\
14story & 0.72 & 1.93 & 0.43 & 1.46 \\
\hline
\end{tabular}

SeismoMatch is an application capable of adjusting earthquake accelerograms to match a specific target response spectrum, using the wavelet algorithm. It is also possible to concurrently match a number of accelerograms, and then obtain a mean matched spectrum whose maximum misfit respects a pre-defined tolerance. Since the matching procedure depends on the fundamental period of structure, the matching procedure was conducted separately for 4, 10, and 14-story BRBFs in SeismoMatch and the corresponding matched records were used in the time history analysis in OpenSees. It should be noted that the frequency content of the records during matching in SeismoMatch software is closely kept unchanged.

\subsection{Response history analysis results}

Nonlinear time history analyses were conducted to assess seismic response of standard and hybrid BRBF at DBE and MCE hazard levels and the maximum of mean absolute values for seismic demands including inter-story and residual story drifts were computed as a result.

Figs. 6a to 6x depict the Inter-Story Drift Demand (IDR) and Residual Drift Demand (RDR) in 4-story, 10-story, and 14-story standard and hybrid BRBFs at two hazard levels. Several statistical quantities of RDR and IDR demands, such as, mean $(\mu)$, standard deviation $(\sigma)$, and $(\mu+\sigma)$ are evaluated for all analytical models under the selected ground motions. The $\mu$ and $(\mu+\sigma)$ values of drift response are represented in Figs 6a to 6x. Furthermore, Tables 7 and 8 synopsize the maximum of mean values of IDR and RDR demands in standard and hybrid BRBFs subjected to selected ground motion records.

As can be deducted from Fig. 6 and Tables 7 and 8, the hybrid BRBs reduce the lateral inter-story drift and specially the residual drift demands in BRBFs. This fact can be associated to the higher strain hardening of stainless steel material and the higher post-elastic stiffness of hybrid BRBF, consequently. As represented in Tables 7 and 8, and also Fig. 6, the inter-story drift demands at DBE hazard level in all braced frames are less than $2 \%$ which is consistent with design rules. Based on the analysis results and data represented in Tables 7 and 8, at DBE hazard level, the hybrid BRBs reduces the inter-story drifts up to $21 \%, 14 \%$, and $2 \%$, in 4,10 , and 14 -story BRBFs, respectively. The corresponding value of RDR reduction is approximately $50 \%$ in all braced frames. Furthermore, according to MCE hazard level, the hybrid BRBs reduce the inter-story drifts up to $11 \%, 14 \%$, and $4 \%$, in 4,10 , and 14-story RBFs, respectively. The corresponding values of RDR reduction at MCE hazard level is almost 50\% in all BRBFs. Based on the time history analysis results, the residual drifts in hybrid BRBFs are significantly lower in comparison to standard BRBFs. Therefore, the hybrid BRBs were found to counteract the low post-yield stiffness of BRBFs. However, hybrid BRBs were found to inconsiderably affect the maximum inter-story

drift demand of BRBFs. The hybrid BRBs could significantly enhance the re-centering capability and reduce the residual drifts of BRBFs, as a result.

The results of this study are in a good agreement with the findings of Atlayan and Charney [20], in which, instead of stainless steel, a low yield point steel was used in the hybrid BRB core to increase the post-elastic stiffness of the braced frames. In the mentioned studies, it was found that by using low-yield-point steel as one of the hybrid BRB core materials, the residual drift demands of braced frames are decreased up to $40 \%$ at all intensities. Likewise, the application of stainless steel as one of the BRB core materials in the hybrid BRBFs proposed in this study, decreased the residual drift demands up to $50 \%$, in comparison to standard BRBF.

\section{Conclusions}

One of the weakness points of a common buckling restrained braced frame is the low post-yield stiffness and thus large residual deformation under moderate to severe ground motions. This phenomenon can be related to the low post-yield stiffness of the core segment in comparison to its elastic stiffness. This paper aims to investigate the application of stainless steel as one of the core materials in hybrid BRBs. The proposed hybrid BRBs include high-performance steel (HPS-70W) and Stainless steel (304L) as the core materials and their response is compared 
to standard BRBs in which only the A572 (Grade 50) steel was used as core material. Nonlinear dynamic time history analyses were conducted in order to compare the seismic performance of standard and hybrid 4,10, and 14-story diagonally braced frames. Results of nonlinear time history analyses indicated that the peak IDR and specially RDR demands of hybrid BRBFs are significantly lower in contrast to standard BRBFs, subjected to the ground
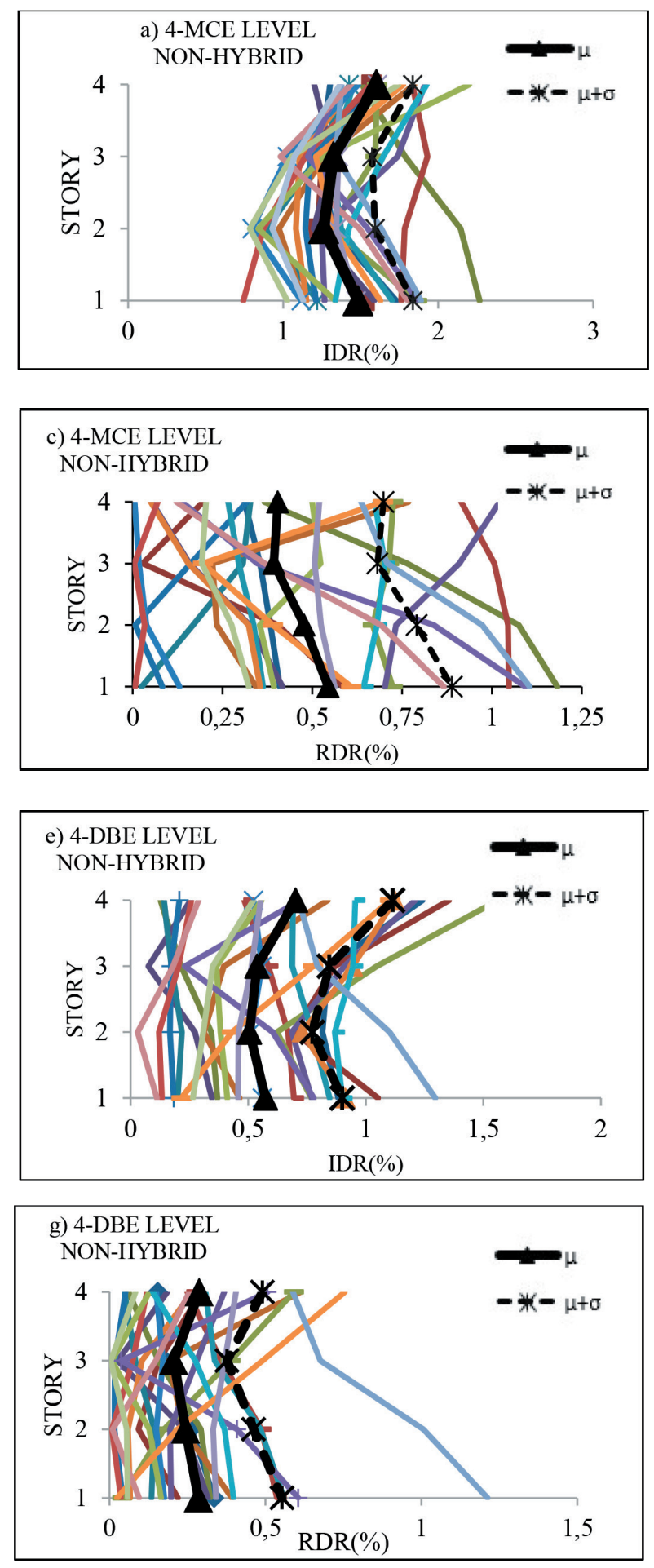

motions scaled to DBE and MCE target spectrums. The hybrid BRBs were found to decrease residual drifts of BRBFs up to $50 \%$ at both DBE and MCE hazard levels. This can be related to the lower yield point and higher strain hardening of stainless steel provided in the core of hybrid BRB. Therefore, the hybrid BRBs could be found as a solution to counteract the low post-yield stiffness and enhance the re-centering capabilities of BRBFs.
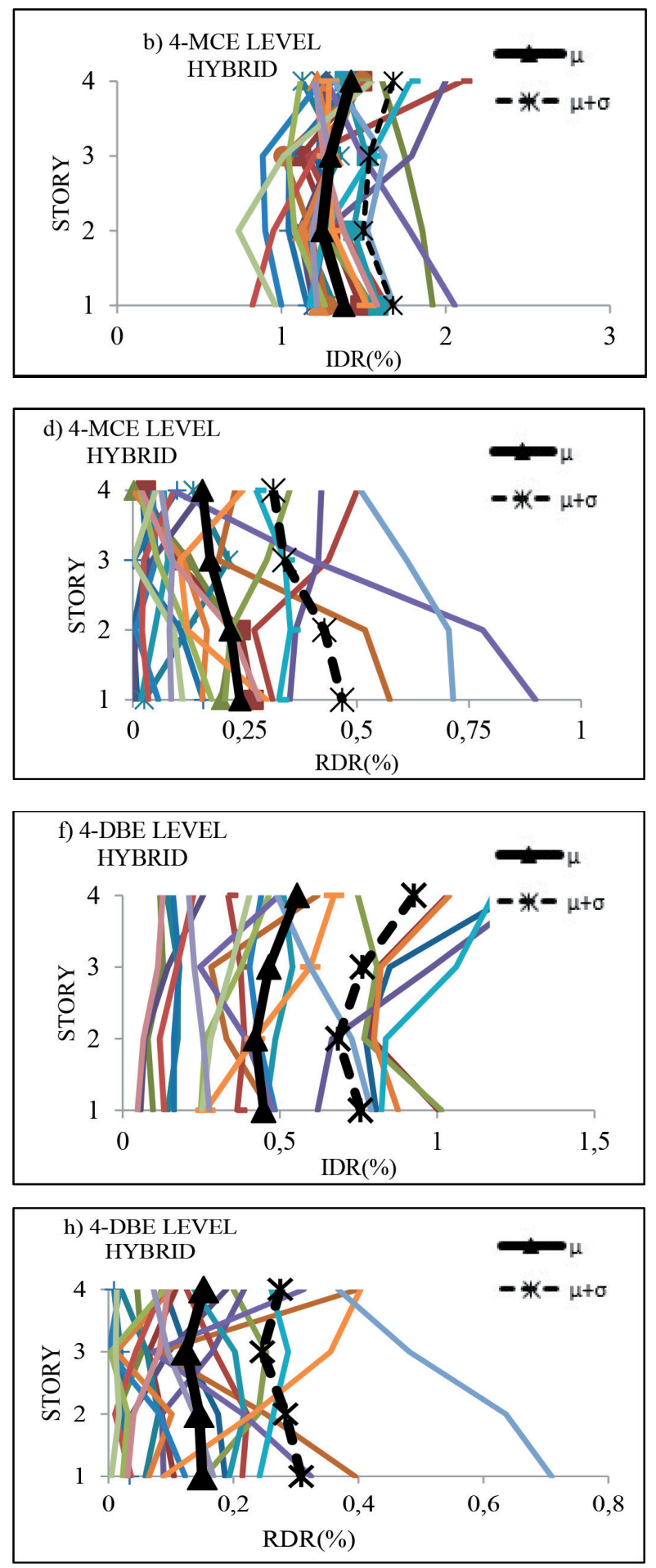

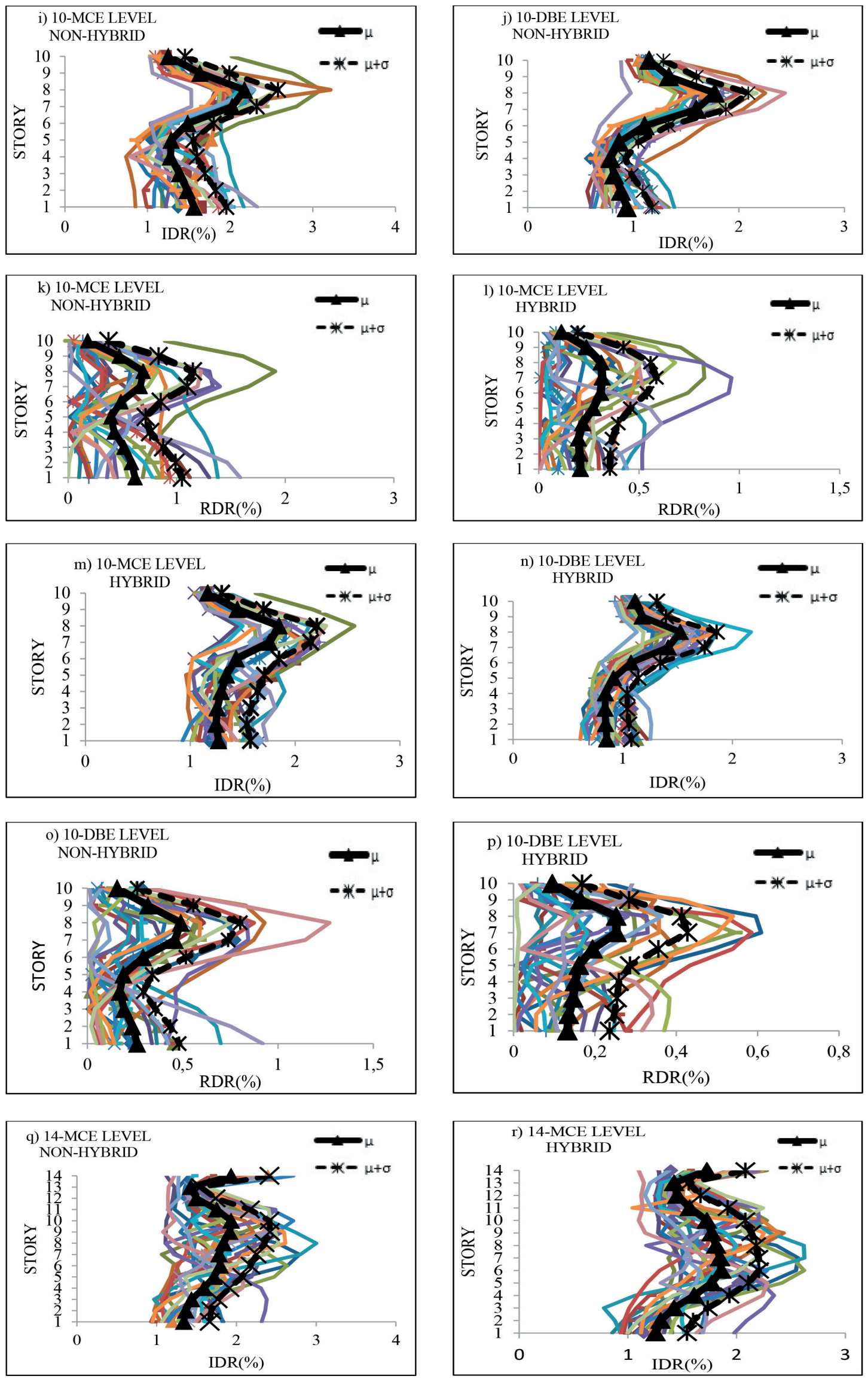

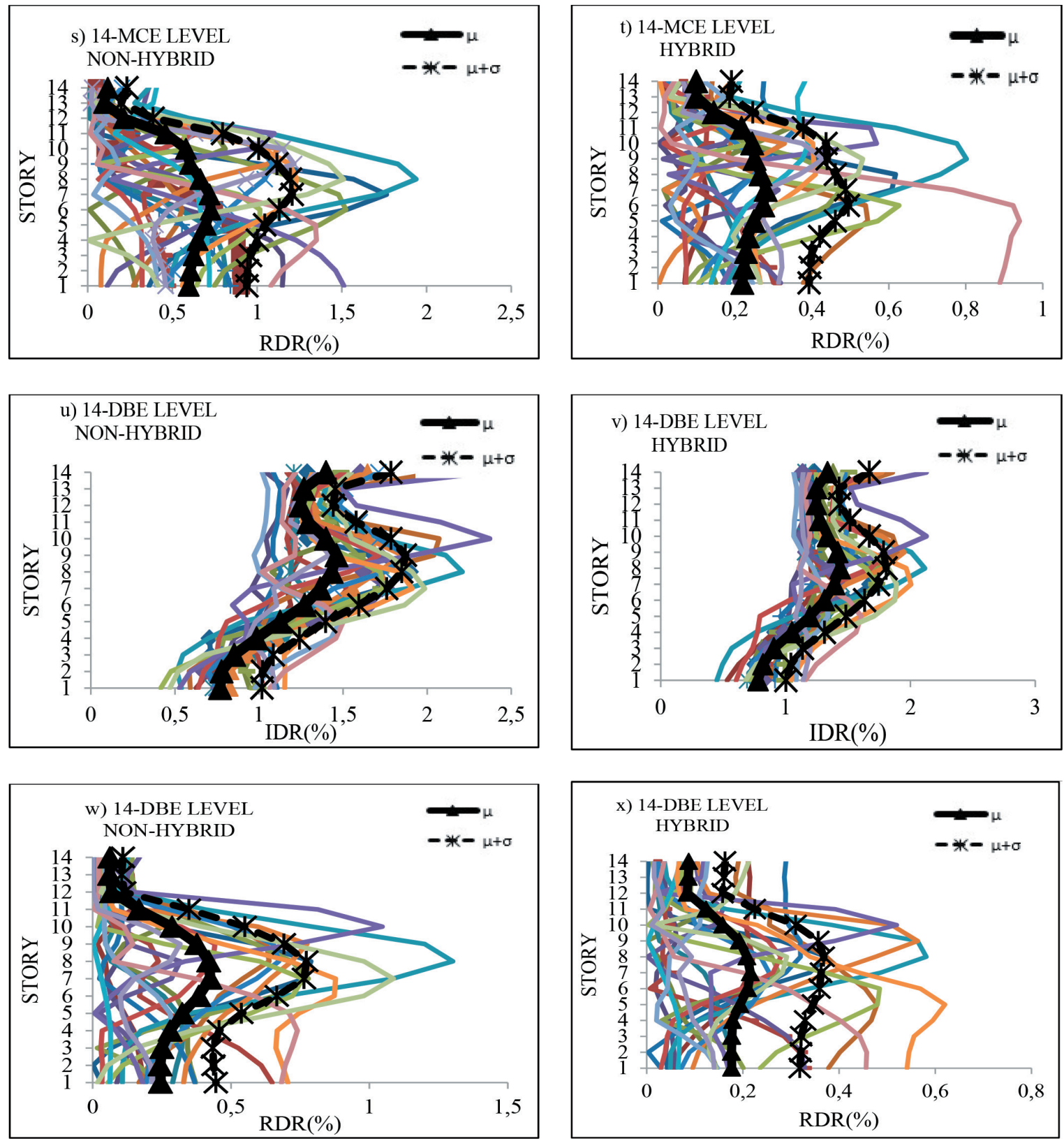

Fig. 6 a) to $x$ ) IDR and RDR demands of BRBFs under selected ground motions

\section{References}

[1] Black, C. J., Makris, N., Aiken, I. "Component testing, stability analysis, and characterization of buckling restrained braced frames", Nippon Steel Corporation, Tokyo, Japan, PEER Report 2002/08, 2002. Available at https://peer.berkeley.edu/sites/default/ files/0208_c._black_n._makris_i._aiken.pdf[Accessed: 06.12.2018]

[2] Inoue, K., Sawaizumi, S., Higashibata, Y. "Stiffening requirements for unbonded braces encased in concrete panels", Journal of Structural Engineering, 127(6), pp. 712-719, 2001. https://doi.org/10.1061/(ASCE)0733-9445(2001)127:6(712)

[3] Xie, Q. "State of the art of buckling-restrained braces in Asia", Journal of Constructional Steel Research, 61(6), pp. 727-748, 2005. https://doi.org/10.1016/j.jcsr.2004.11.005
[4] Clark, P., Aiken, I., Kasai, K., Ko, E., Kimura, I. "Design procedures for buildings incorporating hysteretic damping devices", In: Proceedings, 69th Annual Convention, Santa Barbara, CA, USA, 1999. pp. 355-371. Available at www.siecorp.com/publications/ papers/ida_1999.pdf [Accessed: 06.12.2018]

[5] Sabelli, R., Mahin, S., Chang, C. "Seismic demands on steel braced frame buildings with buckling restrained braces", Engineering Structure, 25(5), pp. 655-666, 2003. https://doi.org/10.1016/S0141-0296(02)00175-X

[6] Hoveidae, N., Rafezy, B. "Overall buckling behavior of all-steel buckling restrained braces", Journal of Constructional Steel Research, 79, pp. 151-158, 2012. https://doi.org/10.1016/j.jcsr.2012.07.022 
[7] Guo, Y.-L., Tong, J.-Z., Zhang, B.-H., Zhu, B.-L., Pi, Y.-L. "Theoretical and experimental investigation of core-separated buckling-restrained braces", Journal of Constructional Steel Research, 135, pp. 137-149, 2017. https://doi.org/10.1016/j.jcsr.2017.04.019

[8] Christopoulos, C., Pampanin, S., Priestley, M. J. N. "Performancebased seismic response of frame structures including residual deformations. Part I: Single degree of freedom systems", Journal of Earthquake Engineering, 7(1), pp. 97-118, 2003. https://doi.org/10.1080/13632460309350443

[9] Pampanin, S., Christopoulos, C., Priestley, M. J. N. "Performancebased seismic response of frame structures including residual deformations. Part II: Multi-degree of freedom systems", Journal of Earthquake Engineering, 7(1), pp. 119-147, 2003. https://doi.org/10.1080/13632460309350444

[10] Wu, C.-L., Loh, C.-H., Yang, Y.-S., Lin, C.-H. "Consideration of collapse and residual deformation in reliability-based performance evaluation of buildings", presented at 13th World Conference on Earthquake Engineering, Vancouver, British Columbia, Canada, August 1-6, 2004. Available at www.iitk.ac.in/nicee/wcee/article/13_716.pdf [Accessed: 06.12.2018]

[11] McCormick, J., Aburano, H., Ikenaga, M., Nakashima, M. "Permissible residual deformation levels for building structures considering both safety and human elements", presented at The 14th World Conference on Earthquake Engineering, Beijing, China, October 12-17, 2008. Available at http://www.iitk.ac.in/ nicee/wcee/article/14_05-06-0071.PDF [Accessed: 06.12.2018]

[12] Pettinga, D., Christopoulos, C., Pampanin, S., Priestley, N. "Effectiveness of simple approaches in mitigating residual deformations in buildings", Earthquake Engineering and Structural Dynamics, 36(2), pp. 1763-1783, 2007. https://doi.org/10.1002/eqe.717

[13] Fahnestock, L. A., Sause, R., Ricles, J. M. "Seismic response and performance of buckling-restrained braced frames", Journal of Structural Engineering, 133(9), pp. 1195-1204, 2007. https://doi.org/10.1061/(ASCE)0733-9445(2007)133:9(1195)

[14] Fahnestock, L. A., Ricles, J. M., Sause, R. "Experimental evaluation of a large-scale buckling-restrained braced frame", Journal of Structural Engineering, 133(9), pp. 1205-1214, 2007. https://doi.org/10.1061/(ASCE)0733-9445(2007)133:9(1205)

[15] Tremblay, R., Lacerte, M., Christopoulos, C. "Seismic response of multi-story buildings with self-centring energy dissipative steel braces", Journal of Structural Engineering, 134(1), pp. 108-120, 2008.

https://doi.org/10.1061/(ASCE)0733-9445(2008)134:1(108)
[16] Hoveidae, N., Tremblay, R., Rafezy, B., Davaran, A. "Numerical investigation of seismic behaviour of short-core all-steel buckling restrained braces", Journal of Constructional Steel Research, 114, pp. 89-99, 2015.

https://doi.org/10.1016/j.jcsr.2015.06.005

[17] Chou, C.-C., Tsai, W.-J., Chung, P.-T. "Development and validation tests of a dual-core self-centering sandwiched buckling-restrained brace for seismic resistance", Engineering Structures, 121, pp. 30-41, 2016. https://doi.org/10.1016/j.engstruct.2016.04.015

[18] Teran-Gilmore, A., Ruiz-García, J., Bojorquez-Mora, E. "Flexible Frames as Self-Centering Mechanism for Buildings Having Buckling-Restrained Braces", Journal of Earthquake Engineering, 19(6), pp. 978-990, 2015. https://doi.org/10.1080/13632469.2015.1011813

[19] Dong, H., Du, X., Han, Q., Hao, H., Bi, K., Wang, X. "Performance of an innovative self-centering buckling restrained brace for mitigating seismic responses of bridge structures with double-column piers", Engineering Structures, 148, pp. 47-62, 2017. https://doi.org/10.1016/j.engstruct.2017.06.011

[20] Atlayan, O., Charney, F. A. "Hybrid buckling-restrained braced frames", Journal of Constructional Steel Research, 96, pp. 95-105. 2014. https://doi.org/10.1016/j.jcsr.2014.01.001

[21] Dusicka, P., Itani, A. M., Buckle, I. G. "Cyclic response of plate steels under large inelastic strains", Journal of Constructional Steel Research, 63(2), pp. 156-164, 2007. https://doi.org/10.1016/j.jcsr.2006.03.006

[22] Beaumont, E., Annan, C. "Cyclic response of structural stainless steel plate under large inelastic strains", presented at Resilient Infrastructure, CSCE Annual Conference, London, Great-Britain, June 1-4, 2016. Available at https:/ir.lib.uwo.ca/csce2016/London/ Structural/48/ [Accessed: 06.12.2018]

[23] OpenSees, University of California, Pacific Earthquake Engineering Research Centre, Berkeley, California, 2007.

[24] Standard 2800, "Iranian code of practice for seismic resistant design of buildings", Building and Housing Research Centre, Tehran, Iran, 2014.

[25] AISC, "Seismic Provisions for Structural Steel Buildings", American Institute of Steel Construction, Chicago, IL, USA, 2010.

[26] ATC 63 "Quantification of building seismic performance", Applied Technology Council for the Federal Emergency Management Agency, Washington, D.C., USA, Rep. ATC 63, 2008.

[27] SeismoMatch, Computer program for spectrum matching of earthquake records. 2016. Available at www.seismosoft.com [Accessed: 06.12.2018] 